\title{
Alleviating some Environmental Impacts resulting from Artisanal and Small-scaleMining Sector: A Critical Review
}

\author{
Byizigiro R. V. ${ }^{1 *}$, Biryabarema M. ${ }^{2}$, Rwanyiziri G. ${ }^{3}$ \\ ${ }^{I}$ Division of Geography, Collegeof Education, University ofRwanda, RukaraCampus, Rwanda \\ ${ }^{2}$ School of Mining and Geology, College of Science and Technology, University of Rwanda, Nyarugenge \\ Campus, Kigali, Rwanda \\ ${ }^{3}$ DepartmentofGeographyandUrbanPlanning / \\ CentreforGeographicInformationSystemsandRemoteSensing (CGIS), CollegeofScienceandTechnology, \\ UniversityofRwanda, P. O. Box 3900, Kigali, Rwanda \\ * Corresponding Author:byizigiro.vaillant@gmail.com
}

\begin{abstract}
This paper highlights the importance of transforming Artisanal and Small-scale Mining (ASM) sector into a more sustainable enterprise and shows the reclamation of despoiled mined sites as an opportunity to return land to beneficial uses which do not compromise future development of the sites. It presents some of environmental impacts produced by ASM and the contribution of a geomorphological approach to alleviate them. The methodology consisted of the review supported by field survey in small-scale mining areas to summarize the most relevant scientific findings and the importance of stabilizing the land that will support sustainably reclamation structures. The impacts include haphazard excavations with no land reclamation plan, pits, trenches inadequately protected, siltation of open water bodies, soil and rock wastes, negative change of soil properties, and accelerated erosion of the mine sites. To transform the sector into a more responsible industry, ASM has to be placed within two integrated perspectives: (i) building the capacity of ASM sector, and (ii) promoting restoration approach by building a critical knowledge mass through collaboration of relevant stakeholders, with emphasis on multidisciplinary approach. The study opens a relevant new research field and emphasises on the collaboration of mining stakeholders including local communities to develop an integrated approach to address challenges that ASM industry is facing in developing countries. This review highlights the impacts of small-scale mining sector on land use potentials and it is essential contribution towards the sustainability of ASM industry and reclamation of despoiled mined lands.
\end{abstract}


Key Words: small-scale mining sector, environmental impact, geomorphologic approach, sustainability

\section{INTRODUCTION}

Small-scale opencast mining is vital in the global supply of some minerals like 'coltan' and gold and provides income for millions of people in many developing countries (Seccatore et al., 2014).Traditionally, in many countries, artisanal mining is operated without prior license and without formal identification of mineral deposits (Kumwimba, 2009). However, in some countries, like Rwanda, this practice is changing and formalization is a requirement before operation, though the entities still largely operate on hand tools basis. Formal Small-scale Mining requires a legal mining license granted after prospection has confirmed the existence of extractable ore (Kumwimba, 2009). The context of ASM is the form where hand tools and /or relatively low-level technology are employed and the mining is largely on the or near surface (shallow) (Byizigiro et al., 2015). It includes Small-Scale Opencast Mining (SSOM) whichessentially involves extraction of surface ores by removing relatively thin covers of soil, sediments or bedrock (Byizigiro et $a l ., 2015)$. This type of superficial mining commonly takes of vegetation and soils, interrupts ecosystem fluxes, and results in loss of valuable farmland (Schueler et $a l, 2011$ ). Such mining practices expose the land to open pitting and trenching rendering the land dangerous to use for other purposes, accelerated soil erosion, aggradation of solid waste on important farm lands, mass movements and silting of surface waters. The uncontrolled human activities aggravate the effects of the natural phenomena of erosion and mass wasting.

The impacts of both anthropogenic and natural processes on affected sites include soil degradation and landscape change, which are especially significant in densely populated regions of developing countries that experience land shortages (Byizigiro and Biryabarema, 2008). Beside its negative effects, ASM is bound to last since there are often no valid alternative 
livelihoods for people in these mining regions, and the attractiveness of quick profit is not sufficiently counterpoised by concern about environment or safety (Seccatore et $a l$., 2014). Some developing countries took initiatives towards assessment of environmental impacts produced by mining operations and re-cultivation of mined degraded land (Rukazambuga, 2008); but the effort is far little to move the small-scale mining sector towards more sustainable development, particularly to assess geomorphic processes specific of SSOM sites in sub-Saharan developing countries (Freak, 1998). Fortunately, the negative impact of SSOM in developing countries has recently moved into the focus of research, covering a variety of disciplines, such as legal, socioeconomic and chemical contamination impacts (Sandell et al., 2018. However, concrete restoration measures and actions are often lacking. In this regard, an increased governmental input, expanded partnerships, and improved dissemination of technology could lead to the development of promising environmental solutions (WuZhenhua et al., 2019).

In support of other disciplines from both natural and social sciences, the purpose of this paper is to highlight the importance of a geomorphologic approach in providing the required skills and regulation regarding reclamation of mining sites. In fact, there is a primordial role of geomorphologic skills in constructing topography and soils that would be stable enough to support sustainably reclamation structures (Toy and Chuse, 2005). Many times, geomorphic processes are often overlooked by mining operators in the evaluation of environment impacts, despite their importance. It is, therefore, vital to continue highlighting their importance and encourage the participation and collaboration of potential stakeholders towards the sustainable SSOM in developing countries. In addition, it is important to underscore the necessity that geomorphic processes, associated with SSOM activities, in all efforts intending to stabilize and recover affected sites for further land uses.

\section{MATERIALS AND METHODS}


In order to get acquainted with environmental impacts resulting from mining operations, this study used the review of existing literature supported by field survey conducted in small-scale mining areas. Regarding the literature review, relevant published and unpublished documents on geomorphologic and environmental impacts resulting from ASM were consulted. In addition, key documents research findings on some approaches of stabilizing the land towards its reclamation have been reviewed. The field survey was conducted in two countries of the African Great Lakes Region, namely Rwanda and Burundi, between from 2007-2015.

For the field visit, a particular attention was paid to: (i) areas under mining activities; (ii) areas of transfer of sediment and earth material proceeding from mined areas; and (iii) areas in low-lying zones before accumulation. On these three locations, particular geomorphic features were identified onsite and offsite, and classified as a direct or indirect impact of human intervention. Finally, block diagrams were constructed based on pictures taken during field survey to representing identified landforms and to showing Landscape evolution within ASM sites and adjacent areas.

\section{RESULTS AND DISCUSSION}

\section{An Overview on Geomorphic Impact of the ASM}

Artisanal and Small-scale Mining has the potential of creating degradation and aggradational landforms as a result of newly initiated or modified natural geomorphic processes, arising from modifications in the landscape. The direct and most spectacular features onsite are of excavational nature such as quarries, pits and trenches; or overburden waste piles or rock dumps. As mentioned in the previous paragraphs, the secondary impacts may well extend on foot slopes and in alluvial plains, beyond the actual mining areas. Braided channels and alluvial fans are among the most encountered associated geomorphic features (Figures 1-3). 

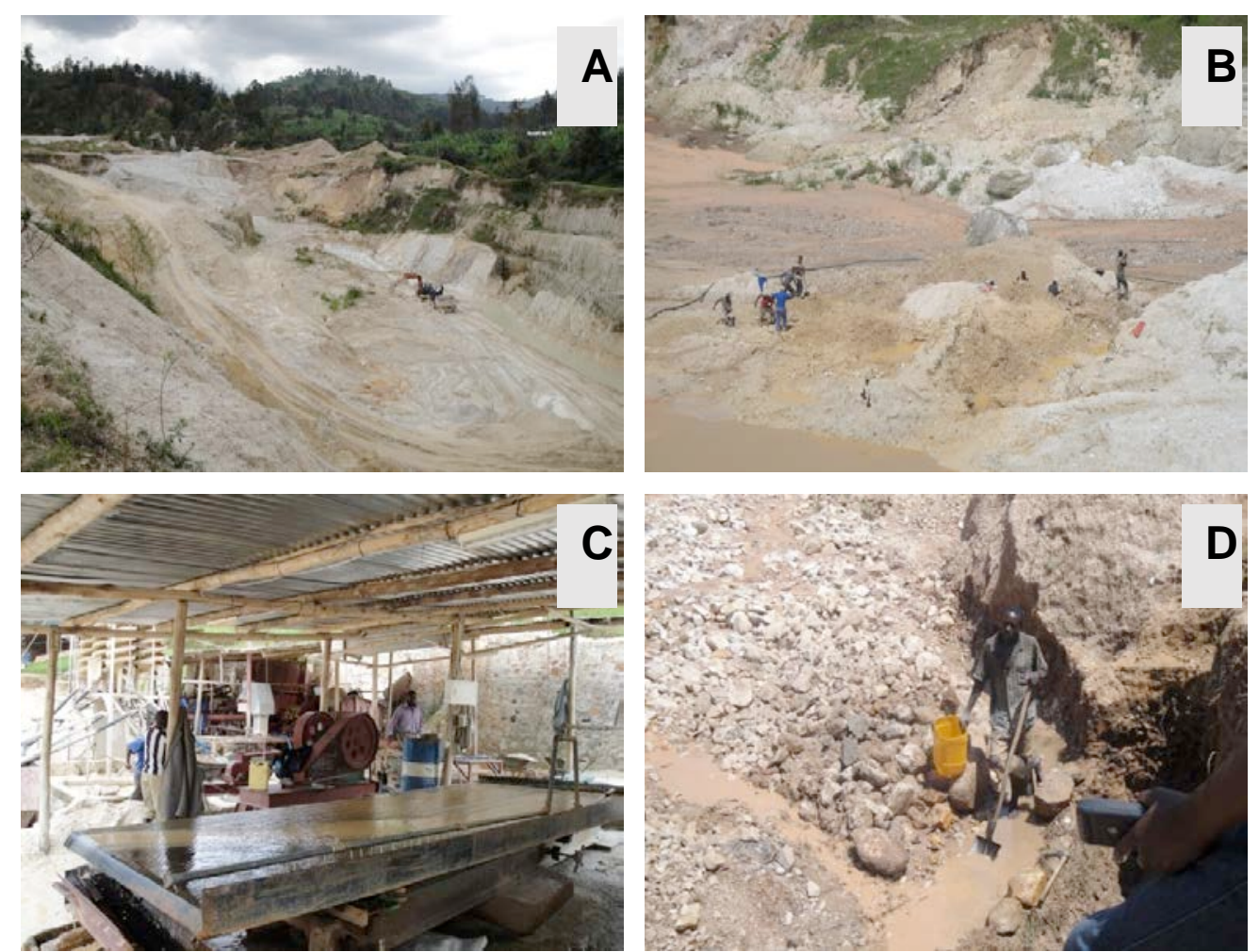

Fig.1. An example of a Dualism of Semi-mechanized and Purely Artisanal Mining Operations in the Gatumba tin-tantalum Mining Sites, Western Rwanda

A - A bulldozer used to excavate ore; B - Alluvial mining using simple hand-held tools (pick, shovel, basins); C Electrical shaking table for mineral concentration $\& \mathbf{D}$ - Ground-sluicing where running water with ore in suspension is flushed into a prepared sluice channel to recover minerals.

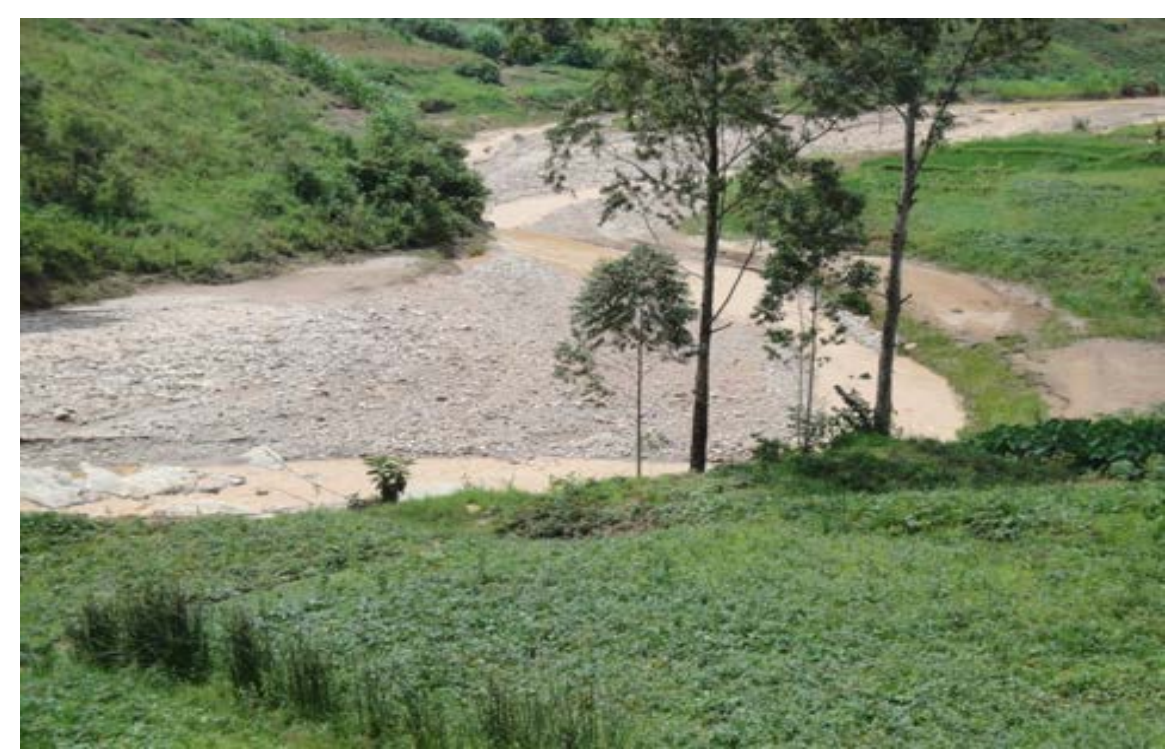

Fig.2. An Example of Off-site Impact of SSOM in Gatumba Mining Sector (Rwanda) showing Devastation of Low-lying Fertile Alluvial Plains by an Abundant Sediment Delivery 
The landscape evolution for the mine sites represented on the two figures above can be represented of the diagram below which is basically a process of levelling-off by increased erosion of topographic highs, and corresponding deposition in topographic lows.

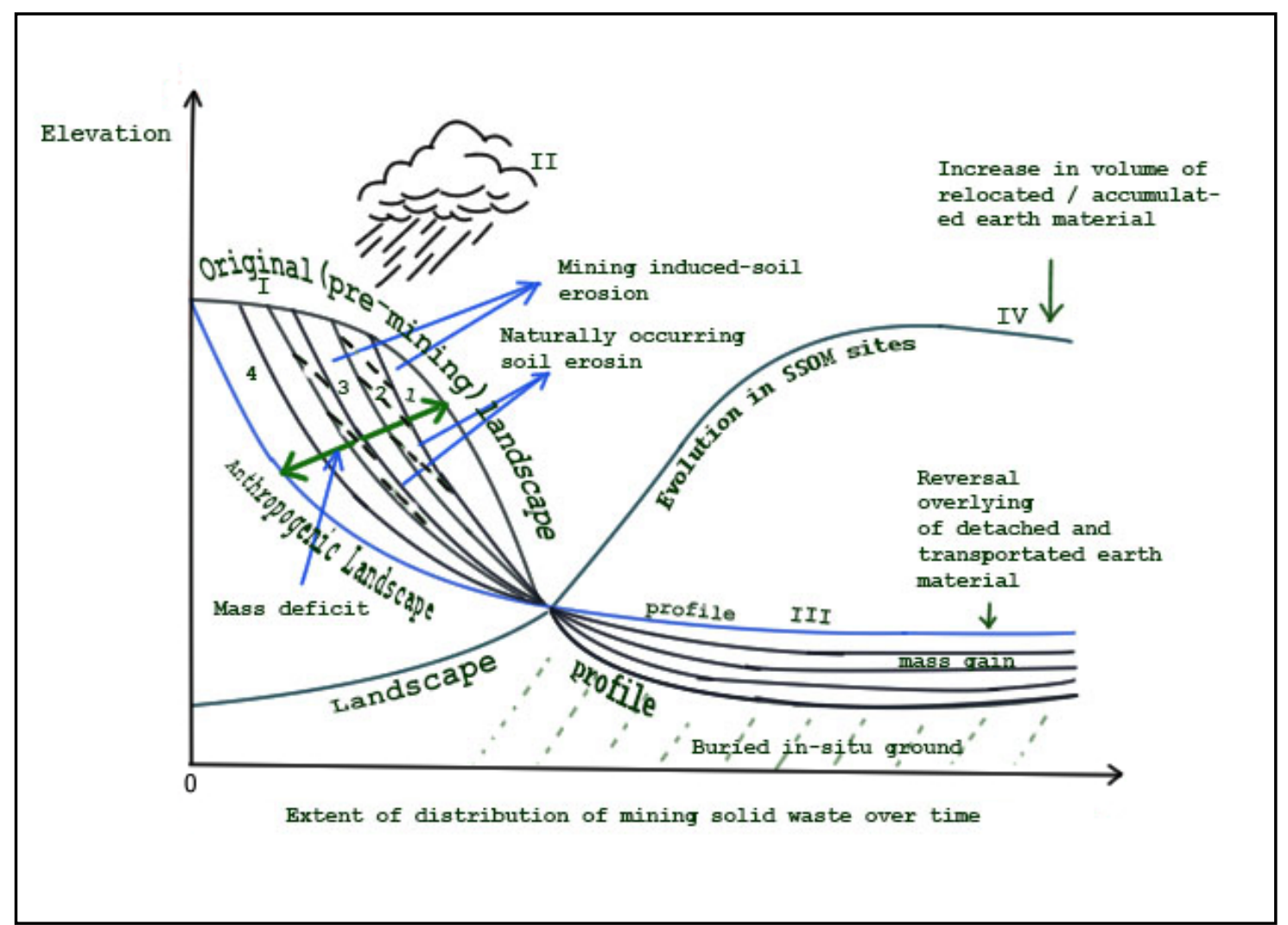

\section{Fig.3: Landscape Development within Small-scale Mining Sites and Adjacent Areas}

I (1-4): On-site opencast mining causing gradual removal of surface earth materials and exposing subsurface geological structures to further mass translocation by (II) natural erosion agents. Off-site effect includes III mass gain which overlies the natural ground in depression and results in increase of volume of relocated earth material IV.

In such conditions, natural processes of soil erosion and earth material under the control of numbers of natural factors including substratum, slope, climate and vegetation among others are intensified or altered. Often operating concomitantly with mining operations, the relative high magnitude of natural process is much more prominent after decommissioning of activities from the site. Pitting and trenching are types of mining and quarrying the most applied in small-scale mining to excavate geological structures. They involve relocation of huge earth material involving farmland and soil loss. This human activities result directly or indirectly in a variety of 
landforms which were classified by Jones (2001) into (i) human-made, (ii) human-induced and (iii) human-modified landforms. These three groups of landforms associated with small scale opencast mining are hypothesised and schematically represented on the diagram (Figure 4) below.

On the one hand, human-made landforms are those produced intentionally, like the removal of overburden material to access the underlying ore in the case of mining activities. They are mostly associated with excavation of geological structures and their exposure to further translocation agents. On the other hand, human-induced landforms are created by natural processes in places and timeswholly dependent on human inducedactivities (Jones, 2001). In opencast mining sites, erosiondevelops action on pits, waste heaps, mine pit walls or in the surroundings where the primary human-made landforms were created. The most identifiable newly created landforms include "rills", formed by surface runoff on pit walls. Piping which becomes one of prominent geomorphic processes is likely to trigger the development of number of landforms in mined sites. Pipes are progressively enlarged with on-going erosion and develop to "gullies", a process that can ultimately lead to the formation of badlands (Byizigiro and Biryabarema, 2008). Once slope failure occurs, there is disturbance of the whole earth-geological fabric. This leads often to the weakening of adjacent areas, particularly on the upper part of the back-slope. This results in the development of "cracks"and decrease of shear or tensile strength which allow the entry of water into weakened zones between blocks (Varnes, 1984;Holl and Aide, 2011). These weakened zones constitute preferably planes for further mass movements from the summit of the pit.

Human-modified landforms are created when the extent of geomorphic processes is changed by human activity. The change in hydrological budget through the removal of protective vegetative cover or the exposure of excavated overburden material to erosion processes is the main mechanism that triggers the formation of such landforms (Jones, 2001). SSOM operations thus 
may indirectly result inslumping along concave stream banks and debris flows may spread downstream, often contributing to the formation of "braided stream channel" system. . According to Goudie (2006), through a lack of understanding of the operation of geomorphologic systems, humans have deliberately and directly altered landforms and processes and have thereby caused a series of events that were neither anticipated nor desired.

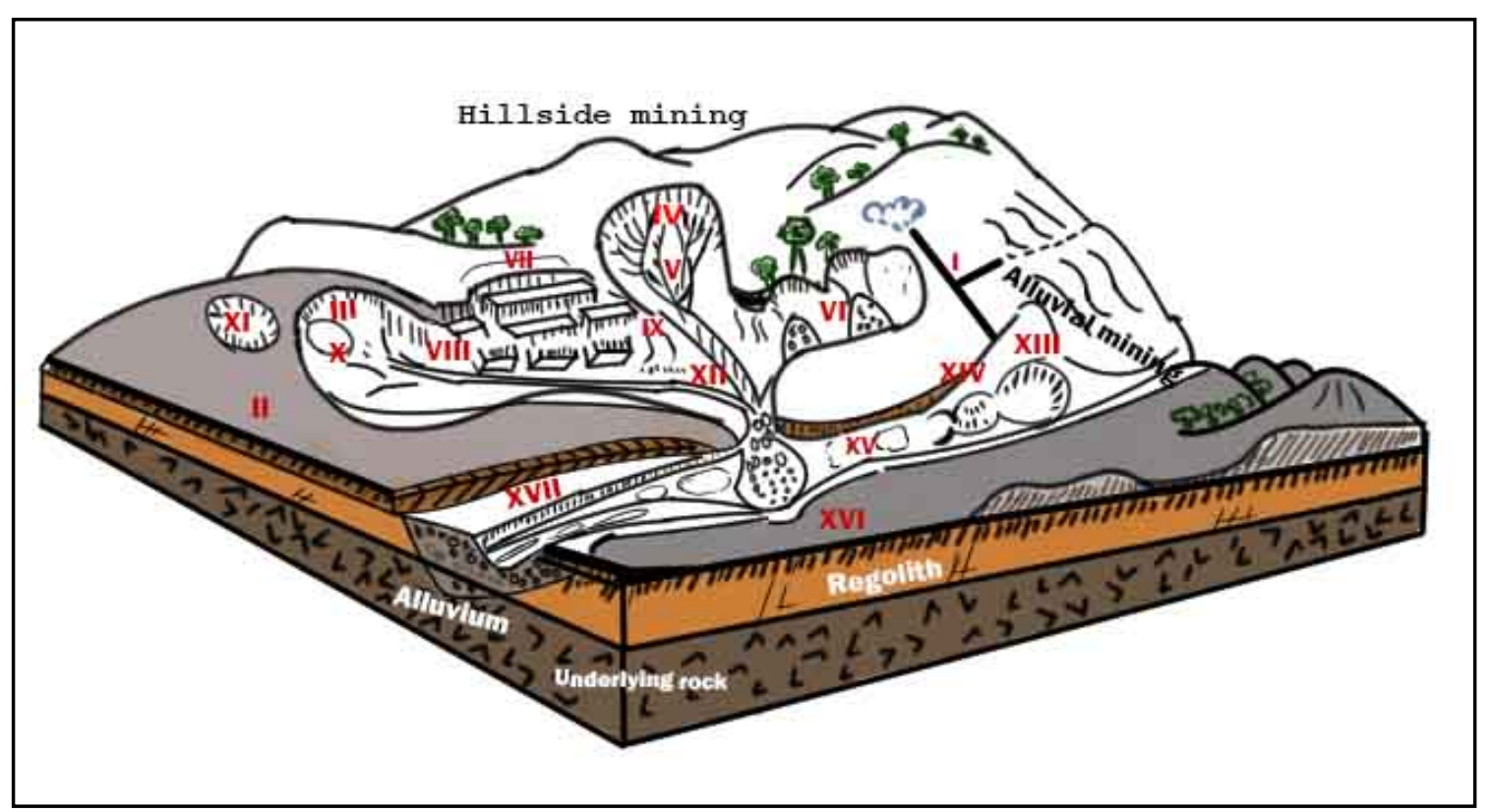

Fig.4.Hypothetical Landforms resulting from SSOM Impacts

(Adapted from Byizigiro et al., 2015)

The figure above represents: I - Mineralized vein/ore which is basically extracted for the search of minerals, II - Stumps of cleared vegetation during the preparation of the ground before mining starts; III Pit wall either sides of the ore being extracted ; IV - Rills developed on pit wall by overflowing water which may enlarge to form V - Gullies, VI - Land slide, VII Slump and VIII - Topples are mass movement depicting the level of weakening of shear and tensile strength; IX - Stack which is an isolated topple; X - Gallery associated with the underground excavation; XI - Sinkhole where the underlying geological structure have been removed through a underground mining; XII - Flow track excavated earth material being relocated downstream by rain of stream water; XIII - Mine Pit a depression expressing a deficit of earth material cause by mining removal process ; XIV - Tailing dump which is a pile of waste accumulated near the pit; XV - Debris flow; XVI - Tailing fan \& XVII - Braided stream channel

\section{Reconstructing Soils and Landforms to Improve the Sustainability of ASM}

Mining operations are renowned to trigger changes in erosion-sedimentation processes and soil properties. Martin-Duque (2010) asserts that the knowledge of soil properties and landforms is fundamental for an understanding of the environmental effects of opencast mining if we expect further reconstruction of mining sites(Wilkinson and McElroy, 2007) . Toy and McElroy (2007) 
underscore the importance of designing the most appropriate strategies for reclamation of mined sites. In this regard, many researchers including Toy and Chuse (2005) and Craul and Rowe (2008) put emphasize on the importance of stabilizing the topography to be reconstructed and the mastery of soil erosion control.

Toy and Chuze (2005) listed ten (10) geomorphic principles that need to be consecutively applied in order to achieve a successful reclamation: 2) reclamation planning and engineering; 2) site characterization; 3) material management; 4) topographic reconstruction; 5) replacement of topsoil or soil substitute; 6) surface manipulation; 7) addition of soil amendments; 8) revegetation; 9) irrigation; and 10) site monitoring and maintenance. According to Ser (2004), an ideal restoration would enable and support similar diversity and community structure in comparison with reference sites, with the presence of indigenous species, and presence of functional groups necessary for long-term stability. The physical environment would be capable of sustaining reproducing populations, and normal functioning that integrates with the landscape and eliminates potential threats. The site should then be self-sustaining and resilient to natural disturbances. Stabilization techniques depend on the individual topography position of the site e.g. pits located in alluvial plains or on hilltops, or trenches on hillside (Rowe, 2008). Reconstruction relates more to the refilling and shaping that provide the site with a topography and profile capable of supporting reclamation practices and complying more or less with the surroundings. Mimicking the original topography and blending it with the surroundings is the best option (Martin-Duque et al., 2010).Many researchers suggest, however, that this maximum requirement might be possible to achieve to variable degree only (Holmberg, 1983;Sandell Festin, 2018).

The type and degree of modification depends strongly on the volume of relief and properties of the material (particularly its stability and whether or not it needs to be covered or protected from 
weathering) (Holmberg, 1983). Furthermore, geological material, if successfully reshaped will enable to achieve: (i) the best ecological conditions for the planned land use; (ii) proper hydrologic structure; and (iii) the most pleasing aesthetic impression; admitting that the three criteria may not be compatible (Holmberg, 2003). Thus, the required topographic modification must be based on the individual site with no universal application. For this, topographic reconstruction becomes an opportunity for creativity and imagination (Crauland Rowe, 2008). The compacted stepped sub-base provides engineered stability of the entire system, as long as the slope, namely the angle of repose of the material to be shaped, is well designed (Crauland Rowe, 2008).

Where applicable, all earth material should be removed in a separate layer from the area subjected to mining and preserved in various piles. In addition, they should be well confined to avoid loss and/or any contamination of the ground. These stockpiles are later used in the process of reclamation, specifically refilling. In most cases, this is not possible due to several reasons highlighted in various discourses: (i) the operators have no capacity and organization to achieve that; (ii) the landscape is strongly hilly with no appropriate locations to store the material or the infrastructure to transport it to the right location; (iii) some of the ASM sites exist for a long time and are always reworked by subsequent operators; etc. However, reconstitution in one way or another has to be planned even if it involves fresh land scarping and re-designing the site for beneficial land use. Whichever approach is applied the following important soil parameters have to be considered: (i) structure and texture; and (ii) humus and mineral content both determining the soil properties responsible for the success of re-vegetation and thus the start of a sustainable land use after mining. 


\section{Assessing ASM Impact in a geomorphologic perspective}

Regarding geomorphic impact assessment and mitigation, effective incorporation of restoration and conservation priorities remain hampered by inadequate knowledge of the natural landform dynamics and the difficulty in designing restoration criteria (Bridges, 1987). Knowledge of geomorphic processes and their importance in reconstituting landscapes degraded by ASM is vital. However, this has to be in concomitant with other key disciplines to successfully restore and re-use such landscapes. Cao Diogo et al.(2017 underscores the importance of collaboration of all stakeholders if we expect a successful reclamation of mine sites. Skills from all disciplines should complement each other but the primordial role of geomorphology skills in the process of restoration of degraded lands has gained broad consensus.

Generally, the mitigation approach of geomorphic processes associated with ASM can be placed within two integrated perspectives. The first one is to build the capacity of ASM sector (technical, financial, managerial) in order to deploy proven approaches to mitigate any adverse land degradation consequences (Holmberg, 1984). This would have to be accompanied with realistic regulatory framework, i.e. converting the sector into a responsible enterprise. The second one is the development of geomorphic restoration approaches through building a scientific database of existing research results and promoting new research activities into building a critical mass of knowledge through collaboration of relevant stakeholders; with strong emphasis on multi-disciplinary approach. A broader consideration can be possible through a harmonized collaboration of all stakeholders including scientists and government ministries and agencies (Rukazambuga et al., 2009).The existence of a comprehensive knowledge would lead to the development of detailed and effective regulations and standards, which would be realistic from the industry point of view and effective from the regulators point of view. According to Byizigiro et al(20015), the mitigation approach of geomorphic processes associated with ASM can be 
facilitated by providing consistent guidelines through legal requirements, technical aspects, practical approaches, organized structures and consistent plans (Fig. 5).

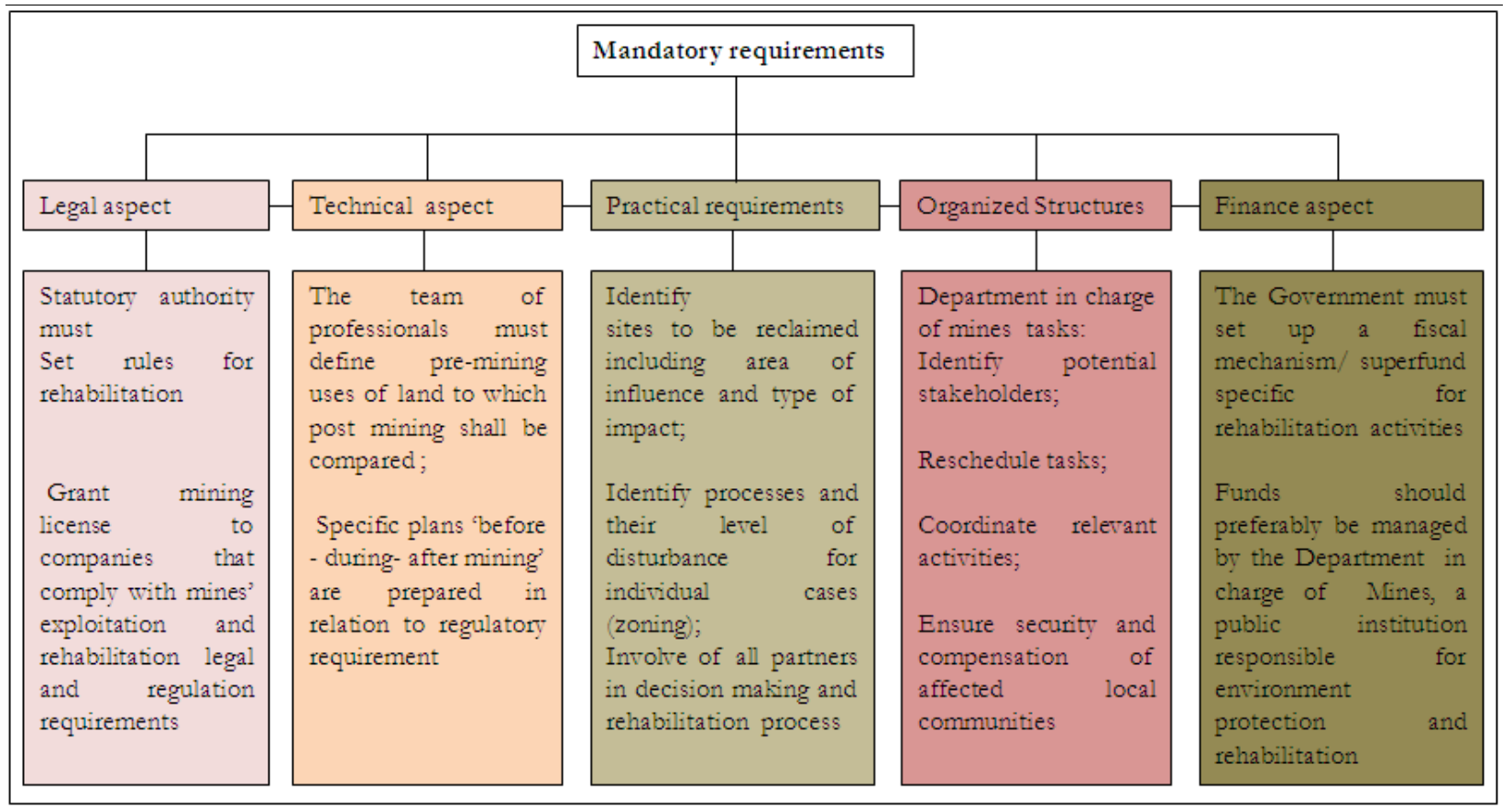

Fig.5. Requirements for the Sustainability of Small-scale Mining Sector

(Adapted from Holmberg, 1983)

\section{Legal Requirements \&Technical Aspects}

For legal requirements, consistent acts for ASM and reclamation should be set and used in developing guidelines. Any reclamation measures should specifically aim at striking a balance between environmental protection and the social-economic benefits of the nation or local people (Manciniand Sala, 2018). The licensing agreement should contain clear articles on progressive land reclamation and final reclamation before decommissioning. The source of reasonable rehabilitation funds has to be included in the agreement. Regarding technical aspects, the development of sustainable land use systems for areas severely affected by ASM is a difficult for three major reasons. Firstly, under natural conditions, landscapes evolve as determined by geology, climate, soil and vegetation cover conditions. The reclaimed soil and cover conditions after reclamation almost always are very different from those before mining (Toy et al., 2002). Secondly, because landscape resources often were not conserved (stockpiled), the exercise of 
reconstructing soil design becomes very difficult (Rowe, 2008). The alternative to import topsoil and other materials from off-site would not be a good option because these materials on an offsite location should probably remain there for eventual restoration of that site unless it is to be totally occupied by structures. Lastly, because many governmental departments are understaffed, minimal commitment has been made to address environmental problems (Veiga et al., 2014). In this regard, the collaboration of all stakeholders as well as the use of multidisciplinary research approaches would be much beneficial.

\section{Practical Approach}

Apart from few research groups, there have been few systematic concrete actions to rehabilitate affected sites and identify those which need more attention and immediate intervention. There has been even less work to quantify the nature and level of associated problems so as to prioritize remediation efforts. In addition, a legacy from decades of old ASM practices continues to exist in most mining operations and the shift towards new ones that comply with environmental safeguard and local people needs isstill slow. All these old practices should be revisited. Thus, orphaned, abandoned and/or owned mines should be identified and the extent of physical impact determined. Within the mines and areas of their influence, levels of disturbancehave to be identified and zoned.Categorization levels of land degradation in zones highly disturbed, zones strongly disturbed and zones moderately disturbed is recommendable in the perspective of allocating appropriate remediation tools and strategies. Furthermore, it would enable to decide whether remediation measures would (i) rely completely upon spontaneous recovery; (ii) or exclusively adopt technical measures; or (iii) to combine both techniques by monitoring spontaneous recovery towards a target (Prach, 2008).

\section{Organized Structures}


The existence of clear frameworks and responsibility between government and stakeholders needs to be well formulated through laws, regulations, mining standards, contracts and agreements. Organized systems are very important for an effective process of rehabilitation. This will usually involve a well-coordinated collaboration of all stakeholders such as mining industries, government ministries and agencies, scientific institutions, local government entities, and local communities (Fig. 6). In addition, a wide range of skills might be involved due to the complexity of the nature and the relevance of the task (France, 2008). The program for reclamation of degraded sites may lead to the development of national approaches, impact assessment, prioritization of areas to be rehabilitated and actions to be carried out, objective setting and developing action plans. These programs could provide useful guidelines for the mining industry. Gavini (2003) and Senos (2008) highlight that sustainable small-scale mining operation and successful landscape management plans will assess not only appropriate mining techniques but also the possibility of rescheduling management tasks, whereby the need for labor, energy as well as material are sensibly reduced. This suggests that required task for a successful restoration could be allocated to appropriate individuals or institutions. Last but not least funding liabilities must be determined and on that basis a budget plan must be set up. 


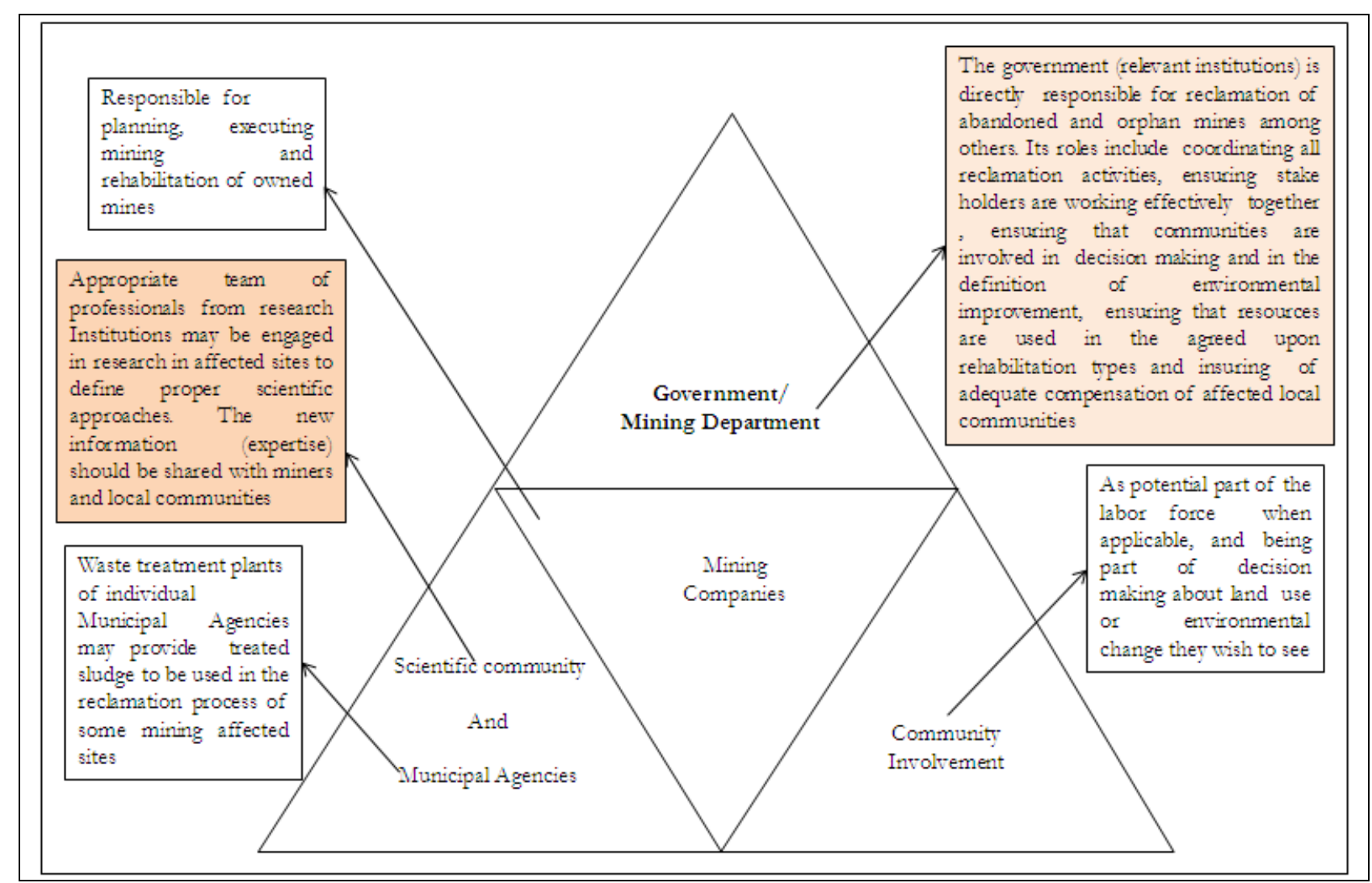

Fig.6: Sharing Tasks to Enable the Re-cultivation of Mined Affected Areas

(Adapted from Freak, 1998; Gavini, 2002; Senos, 2008 \& Holmberg, 1983)

\section{CONCLUSIONS}

Mining is essentially artificial mass movement superimposed on natural mass movement processes. The landscape evolution for the mine is fundamentally a process of levelling-off by intensified erosion of topographic highs, and complementary deposition in topographic lows. Field surveys have shown gradual mass deficit is the direct impact associated with onsite excavation of mineral bearing ore which exposes subsurface geological structures to further mass translocation by natural erosion agents. On the other hand, offsite impact of mining operation includes translocation or accumulation of earth material, and stream siltation which results in mass gain which reversely buries the natural ground in low-lying area. Natural geomorphic agents operating simultaneously or consecutively with mining activities on mined areas result in specific and distinct landforms onsite and offsite locations. 
Understanding mining and post-mining mass movement and associated geomorphic processes and the control of these processes is a fundamental prerequisite toward a successful restoration of mined sites, and the sustainability of the sector. Strategies leading to reclamation mine-affected sites and mitigation of geomorphological impacts cut across number of scientific disciplines, including social and political boundaries. In an inclusive reclamation approach of mined sites stakeholders need to work in synergy with courage and strong commitment. The mining statutory authority in partnership with the scientific community has to develop an interdisciplinary approach and coordinated effort to address this challenge facing the small-scale mining industry of developing countries.

\section{Acknowledgements}

We sincerely thank the anonymous reviewers for their valuable comments that enabled to improve the manuscript.

\section{REFERENCES}

1. Burger, J. a. ( 1999). Using soil quality indicators to assess forest stand management. Forest Ecology and Management, 122:155-166.PII: S 0378-1127(99)00039-0

2. Byizigiro, R. V. (2008). Geomorphologic processes in the Gatumba mining area. In Biryabarema, M., D. Rukazambuga and W. Pohl (Eds), sustainable restitution/recultivation of artisanal mining wastlands in Central Africa- a Pilot Phase. Etudes Rwandaises, 16: 41-50. ISSN: 1014-4874

3. Byizigiro, R. R. (2015). Small-Scale Opencast Mining: An Important Research Field for Anthropogenic Geomorphology. DIE ERDE, 146 (4): 213-231.DOI: 10.12854/erde-14621

4. Bridges, E. (1987). Surveying Derelict Lands. Oxford: Clarendon Press. 137 pp. ISBN: 0198545665

5. Cao Diogo RV, Bizimana M, Neder R, Ntirushwa DTR, Naramabuye F-X, Buerkert A (2017) Effects of compost type and storage conditions on climbing bean on Technosols of Tantalum mining sites in Western Rwanda. J Plant Nutr Soil Sci., 180:482-490.DOI: https://doi.org/10.1002/jpln.201600485 
6. Chuse, T. T. (2005). Topographic reconstruction: a geomorphic approach. Ecological Engineering , 24: 29-35.DOI:10.1016/j.ecoleng.2004.12.014

7. France, R. (2008). Handbook of Regenerative Landscape Design.Boca Raton: CRC Press Taylor \& Francis Group.DOI: https://doi.org/10.1201/9781420008739

8. Freak, G. (1998). Rehabilitation guidelines: A systematic approach to mine waste management in China. - In Fox, H.R., H.M. Moore, and A.D. McIntosh (eds.):Land Reclamation: Achieving Sustainable Benefits , pp. 425-436.-Balkema Publishers, Rotterdam.ISBN: 9058090027.

9. Gavini. (2003). Artisanal and Small-Scale Mining:Challenges and Opportunities. ISBN: 1 853839078

10. Goudie, A. (2006). The Human Impact on the Natural Environment, 5th ed. Oxford: Blackwell Publishers.

11. Holl, KD and Aide, TM (2011). When and where to actively restore ecosystems? Forest Ecology Management, 261:1558-1563. DOI:10.1016/j.foreco.2010.07.004

12. Holmberg, G. V. (1983). Land Use, Soils and Revegetation. In Sendlein L.VA., Yazicihil H., Carlson A.L., and Russell H.K (eds.): Surface Mining Environmental Monitoring and Reclamation Handbook. Amsterdam: Elsevier Science Publishers B.V. ISBN 13: 9780444007919

13. Jones, D. K. (2011). The evolution of Hillslope Processes. In D. L. Higgit, M. E. Lee and M. E. Lee (Eds), Geomorphic Processes and Landscape change: Britain in 1000 years.Oxford, UK: Blackwell Publishers. 320 pp. ISBN: 978-1-444-39942-4

14. Kumwimba, M. J. (2009). La problématique de l'exploitation minière artisanale dans la province du Katanga (cas du District de Kolwezi). Mémoire de licence. Kolwezi, DRC: Unpublished.

15. Kumah, A. (2006). Sustainability and gold mining in the developing world. Journal of Cleaner Production , 14(3-4): 315-323DOI: 10.1016/j.jclepro.2004.08.007.

16. Lahiri-Dutt, K. (2003). Not a small job: Stone Quarrying and Woman Workers in Rajmahal Traps in Eastern India. - In Hilson G. M. (ed.): The Social-Economic Impacts of Artisanal and Small-Scale Mining in Developing Countries. Swets\&Zeitlinger B.V. Lisse, 425-448.ISBN: 9780429224720. DOI: https://doi.org/10.1201/9780203971284

17. Mancini, L and Sala, S. (2018). Social impact assessment in the mining sector: Review and comparison ofindicators frameworks. Resources Policy,57: 98-111. DOI: https://doi.org/10.1016/j.resourpol.2018.02.002. 
18. Martin-Duque, J. M.-M. ( 2010). Restoring earth surface processes through landform design : A 13-year monitoring of a geomorphic reclamation model for quarries on slopes. Earth Surface Processes and Landforms, 35(5) 531-548. DOI: 10.1002/esp.1950.

19. Prach, K. \&. (2008). Spontaneous succession versus technical reclamation in the restoration of disturbed sites. Restoration Ecology , 16(3), 363-366.DOI: 10.1111/j.1526100X.2008.00412.x

20. Sandell Festin, E; Tigabu, M; Mutale, N; Chileshe, M; Syampungani, S. \&Odén, P. C. (2018). Progresses in restoration of post-mining landscape in Africa. Journal of Forestry Research, 30: 381-396. DOI: https://doi.org/10.1007/s11676-018-0621-x

21. Schueler, V. T. (2011). Impacts of Surface Gold Mining on Land use Systems in Western Ghana. A Journal of the Human Environment, 40(5):528-539. 2011. DOI: doi/full/10.1007/s13280-011-0141-9.

22. Seccatore, J. T. ( 2014). A practical approach for the management of resources and reserves in small-scale Mining. Journal of Cleaner Production, 84: 803-808. DOI: 10.1016/j.jclepro.2013.09.031.

23. Senos, R. (2008). Rebuilding Almon Relations: Participatory Ecological Restoration as Community Healing. In France, R. 2008. Handbook of Regenerative Landscape Design. Boca Raton: CRC Press Taylor and Francis Group.DOI: https://doi.org/10.1201/9781420008739.eBook. ISBN: 9780429121715

24. SER, T. (2004). International Primer on Ecological Restoration (available from $h t t p / / w w w . s e r . o r g)$. Tucson, Arizona: Society for Ecological Restoration International .

25. Sopper, W. E. (1992). Reclamation of Mine Land Using Municipal Sludge. In R. Lal and B. A. Stewart (eds) Soil Restoration. Advances in Soil Science, 17: 351-431.ISBN 978-14612-2820-2

26. Rukazambuga, D. M. (2008). Sustainable restitution/re-cultivation of artisanal mining wastlands in Central Africa - a Pilot Study. Etudes Rwandaises, 16: 5-174.

27. Rowe, C. P. (2008). Restoration of Drastically Disturbed Sites. Spectacle Island, Boston Harbor. In France R. L. (ed.). Taylor and Francis Group. (pp. FL 33487-2742: 17-43). Bocca Raton: FL 33487-2742: 17-43.

28. Toy, J. T. (2002). Soil Erosion: Processes, Predictions, Measurements and Control. New York: John Wiley \& Sons.ISBN 0-471-38369-4

29. Veiga, M. M. Angeloci-Santos, G., and Meech, J.A. (2014). Review of barriers to reduce mercury use in artisanal gold mining: Review article. The Extractive Industries and Society, 1: 351-361. DOI: doi.org/10.1016/j.exis.2014.03.004 
30. Wilkinson, B. H. (2007). The impact of humans on continental erosion and sedimentation. . Geological Society of America Bulletin, 119(1-2): 140-156. DOI: 10.1130/B25899.1.

31. Wu, Zhenhua; Lei, Shaogang; Lu, Qingqing and Bian, Zheng-fu(2019). Impacts of Largescale Open-Pit Coal Base on the Landscape Ecological Health of Semi-Arid Grasslands. Remote Sensing, 11(15):1820. DOI: 10.3390/rs11151820 